Voix et Images

voixetimages

\title{
Le Jardin des délices de Roch Carrier
}

\section{Noël Audet}

Volume 1, numéro 3, avril 1976

\section{Gérard Bessette}

URI : https://id.erudit.org/iderudit/200049ar

DOI : https://doi.org/10.7202/200049ar

Aller au sommaire du numéro

Éditeur(s)

Les Presses de l'Université du Québec

ISSN

0318-9201 (imprimé)

1705-933X (numérique)

Découvrir la revue

Citer cet article

Audet, N. (1976). Le Jardin des délices de Roch Carrier. Voix et Images, 1(3), 457-458. https://doi.org/10.7202/200049ar d'utilisation que vous pouvez consulter en ligne.

https://apropos.erudit.org/fr/usagers/politique-dutilisation/ 


\section{Le Jardin des délices de Roch Carrier}

Dàns ce “roman" qu'il vient de publier aux Éditions La Presse 1, on retrouve un Roch Carrier toujours attachant, avec ses lignes de force mais également avec quelques faiblesses plus apparentes.

C'est la même vision généreuse d'une petite collectivité rurale, où les moments épiques le disputent aux rêves démesurés et aux descriptions d'un réalisme tel qu'elles basculent souvent dans le fantastique. La vision est donc cohérente d'un bout à l'autre, et Roch Carrier nous promène sur l'étroite frontière qui sépare le rêve de la réalité sans toujours nous prévenir des débordements de l'un dans l'autre. C'est que la démesure épique loge aussi bien dans la réalité qu'il décrit (témoin, l'incendie de l'église) que dans le rêve (les rêves de Gros-Douillette, demi-délires).

La langue de plus en plus ferme et le style hyperbolique supportent fort bien ces contenus.

Le roman nous laisse toutefois sur notre appétit, car si le branle était donné pour une immense parade symbolique où s'agitent la vie, la mort, la soif du pouvoir..., le récit n'arrive pas à supporter, à organiser, à construire cette vision. 
Le récit en effet se casse trop souvent, et les procédés utilisés pour le relancer sont par trop évidents: tour de parole dans une soirée, appel du rêve à la rescousse, bifurcation du récit sur un seul mot. En bref, la structure du récit paraît trop lâche et les raccords qui recousent le tout beaucoup trop voyants.

Par exemple, le texte démarre avec J. J. Bourdage, superbe escroc qui lance la fièvre de l'or et disparaît poùr pratiquement la moitié du roman. Or il est le fil conducteur du récit, le seul lien qui établirait la continuité à travers tous les épisodes. Il est remplacé par le mythe de l'or, mais cela ne suffit pas pour enlever l'impression de morceaux descriptifs mal insérés dans le récit.

De même, on apprend l'histoire du Notaire Caillouette par le biais de témoins qui sont réunis et jasent: le Cordonnier "raconte" l'histoire des semelles creuses (p. 62) ; ensuite la Couturière rapporte l'épisodè des épaulettes bourrées avec de l'argent, même si elle n'a pas le droit de "raconter cette histoire" (p. 64 et suivantes); puis le Menuisier allait révéler l'affaire du plafond de la maison du Notaire quand la Couturière l'interrompt et raconte «l'histoire de l'oreiller du Notaire" (p. 70 à 72). Le procédé pourrait se justifier; ce qui paraît faible, c'est la répétition formelle d'un même prétexte ou d'une même façon d'embrayer le récit.

De la page 84 à la page 100, on retrouve le même procédé pour décrire un nouveau personnage, Constantin Généreux, maître-chanteur. $\mathrm{Ce}$ récit, déjà relié au récit principal d'une façon très fragile sinon gratuite, est lui-même composé de plusieurs récits-témoignages: page 84 : "Chou Racine raconte"; page 86: «Joseph-la-main-coupée a aussi une histoire à raconter"; page 87: Tristesse Lachance "raconte comment il a été dupé par Constantin Généreux»; page 90: c'est Fred Bouffard qui explique comment Généreux a prostitué ses filles; enfin, à partir de la page 92 , c'est la narrateur qui prend la parole sur le même personnage. Entre les pages 101 et 118, nouvelle rupture du récit par l'épisode des «zizis japonais". Enfin, à la page 118 , le récit retombe sur ses pieds avec le retour de J. J. Bourdage.

Malgré cela, la «mosaïque» ne laisse pas indifférent, loin de là. Mais si l'auteur consentait à serrer de plus près son récit, ses œuvres y gagneraient en intensité narrative et en intérêt tout court.

Noël Audet

1. Le Jardin des délices, Montréal, Éditions La Presse, 1975, 215 pages. 